\title{
SOLOS FLORESTAIS EM FRAGMENTO DE FLORESTA URBANA NA MATA DE DOIS IRMÃOS, RECIFE, PERNAMBUCO, BRASIL
}

\author{
FOREST SOILS IN AN URBAN FOREST REMNANT IN MATA DE DOIS IRMÃOS, RECIFE, \\ PERNAMBUCO STATE, BRAZIL
}

\author{
Maria Salomé de Lima ${ }^{1}$ Fernando José Freire ${ }^{2}$ Luiz Carlos Marangon ${ }^{3}$ Brivaldo Gomes de Almeida ${ }^{4}$ \\ Eberson Pessoa Ribeiro ${ }^{5}$ Renato Lemos dos Santos ${ }^{6}$
}

\begin{abstract}
RESUMO
O remanescente florestal que compõe o Parque Estadual Dois Irmãos (PEDI) é considerado como um dos maiores fragmentos florestais urbanos do Brasil. Há relatos no Parque da ocorrência de frequentes quedas de árvores sadias em condições naturais na reserva, o que pode comprometer seu equilíbrio natural e sua função como fragmento florestal urbano. É provável que este fenômeno possa estar associado com características químicas e físicas dos solos que compõem o PEDI. A presente pesquisa teve como objetivo avaliar química e fisicamente os solos do PEDI, identificando, mapeando e analisando o solo nas áreas de ocorrência de queda das árvores no locus da pesquisa. Foram mapeados 12 pontos de coleta de amostras em área representativa do PEDI. Amostras deformadas foram coletadas nas profundidades $0-0,10 \mathrm{~m} ; 0,10-0,30 \mathrm{~m}$; e $0,30-0,60 \mathrm{~m}$ e amostras não deformadas foram coletadas nas profundidades $0-0,05 \mathrm{~m}$ e $0,10-0,15 \mathrm{~m}$. Nas amostras deformadas determinaram-se todos os atributos químicos e parte dos atributos físicos. Em amostras não deformadas determinaram-se apenas atributos físicos. Os solos do PEDI apresentaram baixa fertilidade natural. Mostraram reação ácida e com elevadas concentrações de $\mathrm{Al}^{3+}$ até $0,60 \mathrm{~m}$ de profundidade, que podem formar barreiras químicas que prejudicam o crescimento das raízes das plantas e podem estar causando a frequente queda de árvores no Parque. Os solos foram, em sua maioria, classificados como de textura argilosa a muito argilosa, muito permeáveis ao movimento vertical e lateral de água. Apresentaram uma elevada variabilidade na condutividade hidráulica e redução abrupta de umidade volumétrica com aplicação de pequenas tensões em camadas superficiais, além de maior retenção de água pelo Latossolo em subsuperfície. Com a finalidade de ampliar as informações e criar um banco de dados para estudos futuros, sugere-se o monitoramento das espécies mais vulneráveis à queda, além de analisar outros elementos químicos e físicos do solo do PEDI, como a abertura de perfis para compreender a dinâmica das raízes pivotantes.
\end{abstract}

Palavras-chave: queda de árvores; atributos químicos e físicos do solo; acidez de solos florestais.

\begin{abstract}
The forest remnant that composes 'Parque Estadual Dois Irmãos' (PEDI) is regarded as one of the largest urban forest fragments in Brazil. There are reports of frequent occurrence of healthy fall trees in the park, in natural conditions, which may compromise its natural balance and its function as an urban forest fragment. Probably, this phenomenon is associated to the chemical and physical properties of the soils comprising PEDI. So, this

1 Bióloga, MSc., Professora de Geografia, Secretaria de Educação do Estado de Pernambuco, CEP 50810-000, Recife (PE), Brasil.salome.lima@yahoo.com.br

2 Engenheiro Agrônomo, Dr., Professor Associado, Universidade Federal Rural de Pernambuco, CEP 52171-900, Recife (PE), Brasil. fernando.freire@ufrpe.br

3 Engenheiro Florestal, Dr., Professor Titular, Departamento de Ciência Florestal, Universidade Federal Rural de Pernambuco, CEP 52171-900, Recife (PE), Brasil. luiz.marangon@ufrpe.br

4 Engenheiro Químico, Dr., Professor Adjunto, Universidade Federal Rural de Pernambuco, CEP 52171-900, Recife (PE), Brasil. brivaldoalmeida@gmial.com

5 Geógrafo, Dr., Professor do Instituto Federal de Educação, Ciência e Tecnologia de Pernambuco, CEP 55600-000, Vitória de Santo Antão (PE), Brasil. eberson.pessoa@vitoria.ifpe.edu.br

6 Engenheiro Agrônomo, Dr., Professor do Instituto Federal de Educação, Ciência e Tecnologia de Pernambuco, CEP 55600-000, Vitória de Santo Antão (PE), Brasil. renato.santos@vitoria.ifpe.edu.br
\end{abstract}

Recebido para publicação em 27/06/2015 e aceito em 9/03/2017

Ci. Fl., v. 28, n. 2, abr. - jun., 2018 
research aimed to evaluate PEDI soils chemical and physically, identifying, mapping and analyzing the soils in the occurrence of falling tree areas at the research locus. Twelve points of sampling in a representative area of PEDI were mapped, where deformed samples were collected at depths $0-0.10 ; 0.10-0.30$ and $0.30-0.60 \mathrm{~m}$, and not deformed samples at depths $0-0.05$ and $0.10-0.15 \mathrm{~m}$. The chemical attributes and part of the physical attributes were determined in the deformed samples. And other physical attributes were determined in the undisturbed samples. The soils of PEDI were low in natural fertility. They have acid reaction and high concentrations of $\mathrm{Al}^{3+}$ to $0.60 \mathrm{~m}$, and this can create chemical barriers that damage the growth of the plant roots and may be the cause of the frequent tree falling in the park. The soils were classified as clayed to very clayed, very permeable to vertical and lateral water movement. They had high variability in hydraulic conductivity and sharp decrease of water volumetric content in applying small stresses in surface layers as well as higher water retention by soil in Oxisol subsurface. In order to extend the information and create a database for future studies, it is suggested the monitoring of the most vulnerable species to fall, and analyzing other chemical and physical properties of PEDI soils, also opening profiles to understand tap root dynamics.

Keywords: falling trees; chemical and physical soil attributes; forest soil acidity.

\section{INTRODUÇÃO}

A Mata Atlântica, considerada a segunda maior floresta tropical pluvial do continente americano, possui uma considerável importância para o equilíbrio ecológico. Antes da colonização europeia, essa floresta ocupava mais de 1,3 milhões de $\mathrm{km}^{2}$ da América do Sul, e atualmente, só ocupa pouco mais de $7 \%$ do continente (INSTITUTO BRASILEIRO FLORESTAL, 2015). É muito rica em biodiversidade e espécies endêmicas, sendo caracterizada como um dos hotspot do mundo (MITTERMEIER et al., 2005).

Por muitos anos foi intensamente desmatada e fragmentada com os ciclos econômicos e o processo de urbanização. Estima-se que a floresta foi reduzida a 250.000 fragmentos, destes apenas $17 \%$ apresentam área superior a 50 ha (RIBEIRO et al., 2009). Muitas áreas urbanas costeiras ainda possuem remanescentes de Mata Atlântica, como em Recife, no estado de Pernambuco. Estes fragmentos de Mata Atlântica urbanos proporcionam mais equilíbrio nas condições climáticas locais, amenizando os efeitos causados nas cidades por elevadas precipitações pluviométricas e temperaturas extremas (LEAL; BIONDI; BATISTA, 2014).

A maior parte da Mata Atlântica da zona da mata de Pernambuco foi dizimada desde o período colonial, principalmente para a exploração canavieira e a urbanização. Após o desmatamento, nos primeiros anos de exploração agrícola das terras, era comum se obter elevadas produtividades nos canaviais, entretanto, à medida que o número de ciclos de cultivo aumentava, se reduzia a produção, levando os produtores de cana-de-açúcar ao abandono das terras esgotadas e exploração de novas áreas. Isso porque, ao contrário do que se acreditava, os solos sob a Mata Atlântica apresentam baixa fertilidade natural (ESPIG et al., 2008).

De uma maneira geral, os solos da Zona da Mata pernambucana são classificados como Argissolos e Latossolos (JACOMINE et al., 1973), que de acordo com o sistema brasileiro de classificação de solos (SANTOS et al., 2013) são classes muito evoluídas e intemperizadas. Como consequência da intensa ação dos processos de formação, há remoção dos cátions trocáveis de caráter básico $\left(\mathrm{Ca}^{2+}, \mathrm{Mg}^{2+}, \mathrm{K}^{+} \mathrm{e}\right.$ $\mathrm{Na}^{+}$) e concentração residual de cátions trocáveis de caráter ácido, principalmente o $\mathrm{Al}^{3+}$ (SANTOS et al., 2013). Deste modo, esses solos apresentam-se ácidos, com baixa disponibilidade de nutrientes e elevada saturação por $\mathrm{Al}^{3+}$, podendo restringir o desenvolvimento das raízes, causar efeitos negativos na nutrição e, principalmente em períodos secos, a consistência extremamente dura desses solos, pode comprometer a sustentação das plantas.

A demanda nutricional para a manutenção da exuberante floresta que se desenvolve nestes solos, não é atendida pela quantidade de nutrientes disponíveis neles, mas em sua maior parte pela ciclagem de nutrientes, especialmente pela contribuição da camada orgânica que se desenvolve nestes ambientes, formada pela deposição de serapilheira. Deste modo, apesar de solos extremamente pobres, a densa e vigorosa formação vegetal que se desenvolve sob eles, é quase que exclusivamente mantida pela ciclagem de nutrientes (ESPIG et al., 2009).

Por outro lado, a pobreza química destes solos, aliada a características físicas desfavoráveis à sustentação das árvores, pode ocasionar perdas significativas de espécies mais vulneráveis ao tombamento. Em fragmentos florestais urbanos, como o do Parque Estadual Dois Irmãos (PEDI) tem-se observado uma

Ci. Fl., v. 28, n. 2, abr. - jun., 2018 
frequente perda de árvores sadias, impactando, inclusive em seus indicadores fitossociológicos. Para a realização deste estudo foi constatada a queda de 52 árvores de diferentes espécies nas principais trilhas do PEDI. É possível que os atributos químicos e físicos dos solos deste ambiente estejam favorecendo a intensificação desse fenômeno, o que justifica um estudo mais aprofundado das características químicas e físicas dos solos do PEDI.

Nesse sentido, o objetivo desta pesquisa foi avaliar as características químicas e físicas dos solos que compõem o fragmento florestal urbano do PEDI.

\section{MATERIAL E MÉTODO}

A pesquisa foi desenvolvida no Parque Estadual Dois Irmãos (PEDI), situado geograficamente à noroeste da cidade do Recife-PE, entre as coordenadas $07^{\circ} 59^{\prime} 30^{\prime \prime}$ e $08^{\circ} 01^{\prime} 00^{\prime \prime}$ de latitude Sul e $34^{\circ} 56^{\prime} 30^{\prime \prime}$ e 34'57'30" de longitude Oeste. O Parque atualmente ocupa 1.161 ha e pode ser considerado como um dos maiores fragmentos de Mata Atlântica em área urbana de Pernambuco (LIMA; CORRÊA, 2005). O clima é o tropical litorâneo úmido do tipo As', com temperaturas médias mensais superiores a $25,5^{\circ} \mathrm{C}$. Com índices pluviométricos anuais, acima de $1.600 \mathrm{~mm}$ e com umidade relativa do ar em torno de $80 \%$ (MOREIRA; GALVÍNCIO, 2007).

A cobertura vegetal é um fragmento de Floresta Ombrófila Densa de Terras Baixas. A estrutura geológica é constituída por terrenos sedimentares da Formação Barreiras da idade pliopleistocênica composta por sedimentos arenoargilosos (COUTINHO; LIMA FILHO; SOUZA NETO, 1998). Os solos são constituídos pelos Latossolos Amarelos, Argissolos Amarelos e Gleissolos, predominando os Latossolos e Argissolos argilosos.

Foram coletadas amostras de solo em 12 pontos do PEDI, em uma trilha representativa do Parque, previamente georreferenciada (Figura 1). Cerca de 33 e $67 \%$ dos pontos se situaram em solos classificados como Latossolo Amarelo e Argissolo Amarelo, respectivamente. Em cada ponto de coleta foram retiradas três amostras deformadas, por meio de tradagem, nas profundidades de $0-0,10 \mathrm{~m} ; 0,10-0,30 \mathrm{~m}$; e $0,30-0,60 \mathrm{~m}$, retirando-se aproximadamente $300 \mathrm{~g}$ de solo em cada coleta; e duas amostras não deformadas com o uso de anéis volumétricos, nas profundidades de $0-0,05 \mathrm{~m}$ e $0,10-0,15 \mathrm{~m}$.

Nas amostras deformadas foram realizadas análises físicas e químicas. Fisicamente foi determinada a granulometria para definição de sua classe textural e densidade de partículas. A granulometria foi determinada pelo método da pipeta (RUIZ, 2005) e a densidade de partículas pelo método do balão volumétrico (EMBRAPA, 1997).

Quimicamente, foi determinado $\mathrm{pH}, \mathrm{Ca}^{2+}, \mathrm{Mg}^{2+}, \mathrm{K}^{+}, \mathrm{Na}^{+}, \mathrm{Al}^{3+},(\mathrm{H}+\mathrm{Al})$ e P. O pH foi determinado em água, na proporção de 1:2,5. $\mathrm{O} \mathrm{Ca}^{2+}, \mathrm{Mg}^{2+}$ e $\mathrm{Al}^{3+}$ foram extraídos com $\mathrm{KCl} 1 \mathrm{~mol} \mathrm{~L}^{-1}$, sendo o $\mathrm{Ca}^{2+} \mathrm{e}$ $o \mathrm{Mg}^{2+}$ dosados por espectrofotometria de absorção atômica e o $\mathrm{Al}^{3+}$ por titulação. $\mathrm{O} \mathrm{K}^{+}, \mathrm{Na}^{+}$e $\mathrm{P}$ foram extraídos por Mehlich-1, sendo o $\mathrm{K}^{+}$e $\mathrm{Na}^{+}$dosados por fotometria de chama e o $\mathrm{P}$ por colorimetria. $\mathrm{O}$ $(\mathrm{H}+\mathrm{Al})$ foi extraído com acetato de cálcio a pH 7,0 e determinado por titulação. Todas as análises químicas seguiram as metodologias propostas pela EMBRAPA (2009). Com estes dados calculou-se a capacidade de troca de cátions efetiva $(\mathrm{t})$ e potencial $(\mathrm{T})$, a saturação por bases $(\mathrm{V})$ e a saturação por $\mathrm{Al}^{3+}(\mathrm{m})$.

Nas amostras não deformadas foram analisadas a densidade do solo; a macro, a meso, a micro e a criptoporosidade, além da porosidade total; a curva de retenção de água no solo, a partir das tensões de 1; 6; e $10 \mathrm{kPa}$, na mesa de tensão e de 33,3; 500; e $1.500 \mathrm{kPa}$ no extrator de Richards; a condutividade hidráulica saturada; e calculada a água disponível. As curvas de retenção de água no solo foram ajustadas com o modelo matemático indicado por Van Genuchten (1980).

Para a determinação da condutividade hidráulica, nas amostras de textura mais arenosas foi aplicado o método do permeâmetro de carga constante e nas amostras mais argilosas, o de carga decrescente (EMBRAPA, 1997). 


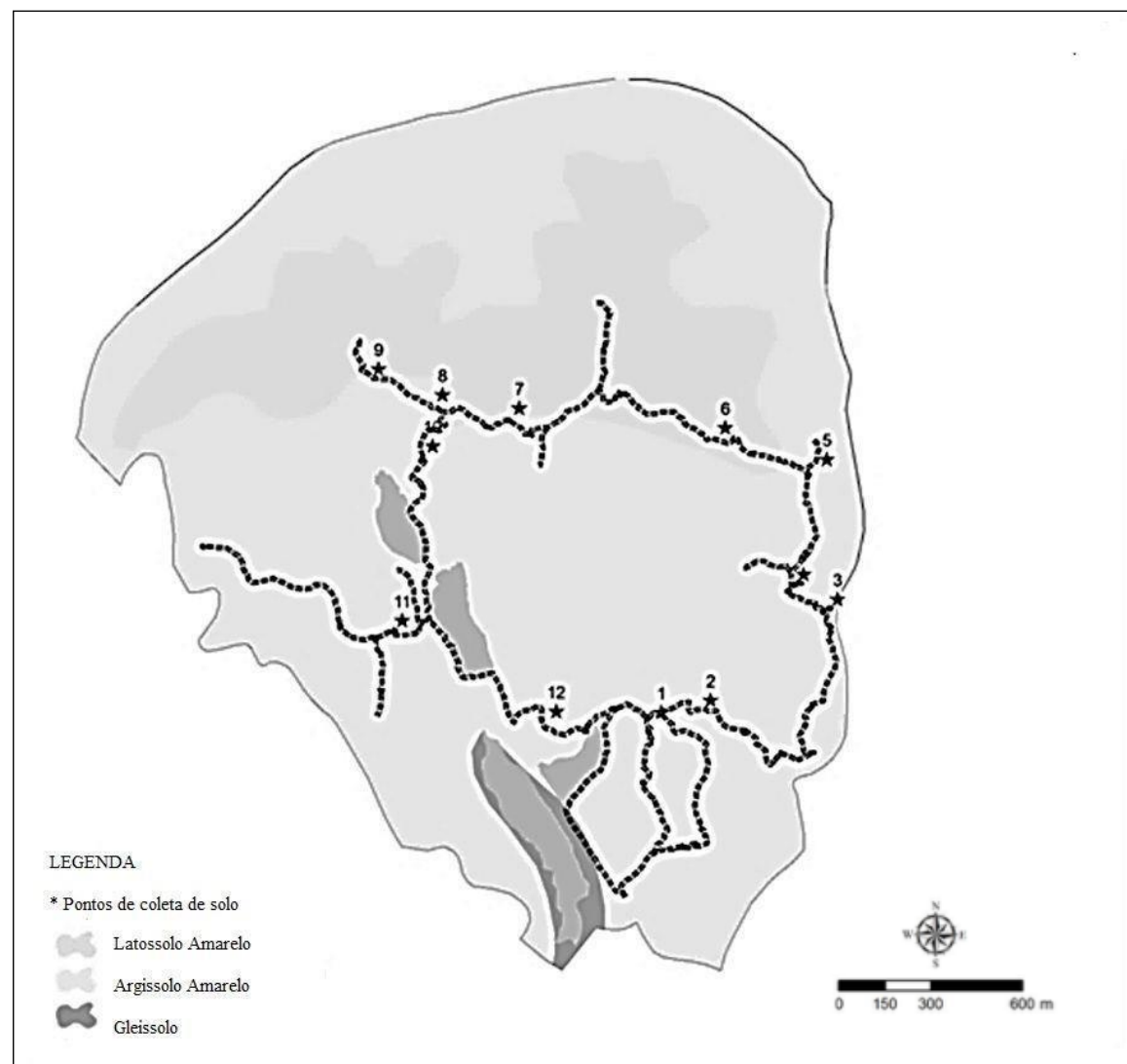

FIGURA 1: Classes de solos e mapa de localização dos pontos de coleta das amostras de solo no Parque Estatual Dois Irmãos (PEDI), em Pernambuco.

FIGURE 1: Soil classes and map of location of soil collection samples in the State Park 'Dois Irmãos' (PEDI) in Pernambuco state.

\section{RESULTADOS E DISCUSSÃO}

Os valores de $\mathrm{pH}$ nas camadas de $0-0,10 \mathrm{~m}$, de $0,10-0,30 \mathrm{~m}$ e de $0,30-0,60 \mathrm{~m}$ variaram de 3,84 a 4,45 , de 3,83 a 4,50 e de 3,71 a 4,76 , respectivamente (Tabela 1). Deste modo, os solos do PEDI apresentaram reação ácida, independentemente da classe do solo. De acordo com a classificação química de Alvarez et al. (1999), solos com pH entre 4,5 e 5,0 são de acidez elevada e abaixo de 4,5 de acidez muito elevada, enquadrando-se nesta última classe todas as amostras das camadas superficiais e mais da metade das amostras das camadas mais subsuperficiais. Segundo a classificação da EMBRAPA (2009), os solos do PEDI foram avaliados como extremamente ácidos, pois o $\mathrm{pH}$ ficou abaixo de 4,5 , exceto em $42 \%$ das amostras da camada subsuperficial, que apresentou pH muito ácido.

$\mathrm{O}$ pH é uma das propriedades químicas do solo de significativa importância, porque relacionase diretamente com a disponibilidade de nutrientes e de elementos tóxicos. Como regulador desta disponibilidade, afeta a nutrição florestal, na medida em que os nutrientes se tornam indisponíveis e, como efeito mais deletério, o $\mathrm{pH}$ quando de reação muito ácida, pode solubilizar demasiadamente elementos químicos que, em concentrações muito elevadas no solo podem causar toxidez nas plantas, causando injúrias em raízes, como é o caso do $\mathrm{Al}^{3+}$. Segundo Caldas (2007), a elevada acidez ativa (pH) em regiões com elevada precipitação pluviométrica é normal, porque ocorre lixiviação de cátions de caráter básico e a concentração residual de cátions de caráter ácido, produtores de $\mathrm{H}^{+}$. Particularmente no PEDI, no qual as precipitações pluviométricas são elevadas era de se esperar um caráter mais ácido dos solos, como encontrado nas amostras avaliadas (Tabela 1).

Em florestas tropicais, há uma tendência natural dos solos apresentarem uma reação mais ácida, principalmente devido à mineralização da matéria orgânica. Se por um lado isto pode comprometer 
a disponibilidade de nutrientes, por outro lado, essa mesma matéria orgânica é produtora de ácidos orgânicos que quelatizam elementos que, em concentrações elevadas podem se tornar tóxicos. Essa mesma mineralização, responsável pela reação mais ácida dos solos florestais, também responde pela disponibilidade de nutrientes por meio da ciclagem, proporcionada pela mineralização. Portanto, sistemas em equilíbrio natural encontram seus meios para harmonizar efeitos positivos e negativos.

Os teores de $\mathrm{Ca}^{2+}$ nas profundidades estudadas variaram de 0,05 a $0,35 \mathrm{cmol}_{c} \mathrm{dm}^{-3}$ (Tabela 1). Entretanto, foram maiores na camada superficial, com média de $0,24 \mathrm{cmol}_{\mathrm{c}} \mathrm{dm}^{-3} \mathrm{e}$ decresceram com a profundidade, até $0,07 \mathrm{cmol}_{\mathrm{c}} \mathrm{dm}^{-3}$, em média. Na classificação apresentada por Tomé Júnior (1997), as concentrações de $\mathrm{Ca}^{2+}$ encontradas nas amostras de solo do PEDI são baixas, pois foram inferiores a 2,0 $\mathrm{cmol}_{\mathrm{c}} \mathrm{dm}^{-3}$, enquanto que, para Alvarez et al. (1999), os valores de $\mathrm{Ca}^{2+}$ encontrados são classificados como muito baixos, por se situarem abaixo de $0,4 \mathrm{cmol}_{\mathrm{c}} \mathrm{dm}^{-3}$. É comum a perda de cátions básicos, como o Ca em solos tropicais, principalmente em regiões em que a precipitação pluviométrica é elevada, como no PEDI. Isto não significa que o fragmento se encontra nutricionalmente deficiente em Ca. É um elemento de funções estruturais nas plantas, portanto, em ambiente em equilíbrio, pequenas ciclagens anuais são suficientes para atender a sua demanda.

Como no caso do $\mathrm{Ca}^{2+}$, os teores de $\mathrm{Mg}^{2+}$ decresceram com a profundidade, nas camadas de $0,0-0,10$ $\mathrm{m}$, de $0,10-0,30 \mathrm{~m}$ e de $0,30-0,60 \mathrm{~m}$ variaram de 0,03 a 0,42 , de 0,04 a 0,19 e de 0,02 a $0,18 \mathrm{cmol}_{\mathrm{c}} \mathrm{dm}^{-3}$, respectivamente (Tabela 1). Cerca de $42 \%, 67 \%$ e $92 \%$ das amostras, da camada superficial até a mais profunda, apresentaram teores de $\mathrm{Mg}^{2+}$ muito baixos, considerando $0,15 \mathrm{cmol} \mathrm{dm}_{\mathrm{c}}^{-3}$ como limite superior da classe adequada (ALVAREZ et al., 1999). Segundo este mesmo autor, o nível crítico para teor ótimo de $\mathrm{Mg}^{2+}$ é de 0,90 $\mathrm{cmol}_{\mathrm{c}} \mathrm{dm}^{-3}$, bem longe dos teores encontrados nos solos do PEDI.

Os teores de $\mathrm{K}^{+}$variaram de 0,02 a 0,14 , de 0,02 a 0,06 e de 0,01 a $0,17 \mathrm{cmol}_{\mathrm{c}} \mathrm{dm}^{-3}$ na profundidade de $0,0-0,10$, de $0,10-0,30$ e de $0,30-0,60 \mathrm{~m}$, respectivamente (Tabela 1 ). Apenas duas e três amostras na camada superficial e na mais profunda, respectivamente, situarem-se dentro da classe média de disponibilidade de $\mathrm{K}^{+}$(ALVAREZ et al., 1999). Considerando as classes de disponibilidade de $\mathrm{K}^{+}$no solo propostas por Alvarez et al. (1999), da superfície até a camada mais profunda, $55 \%$ e $31 \%$ das amostras encontraram-se na classe baixa e muito baixa, respectivamente. Por outro lado, levando em consideração a classificação proposta por Tomé Júnior (1997), cerca de $92 \%$ das amostras de solo enquadraram-se na classe muito baixa, que tem como limite superior o teor de $0,12 \mathrm{cmol}_{c} \mathrm{dm}^{-3}$. Como referenciado para $\mathrm{Ca}^{2+}$, a baixa disponibilidade de $\mathrm{K}^{+}$ nos solos do PEDI se deve a sua vulnerabilidade à lixiviação (SANTOS, 2011).

Os teores de $\mathrm{K}^{+}$dos solos do PEDI foram próximos aos de $\mathrm{Na}^{+}$, com médias de $0,07,0,04$ e 0,05 $\mathrm{cmol}_{\mathrm{c}} \mathrm{dm}^{-3}$, da camada superficial até a mais profunda, respectivamente (Tabela 1). Tanto o $\mathrm{K}^{+}$, como o $\mathrm{Na}^{+}$apresentam elevada mobilidade no solo, sendo baixos os seus teores em solos mais evoluídos (ESPIG et al., 2009; CUNHA et al., 2014), como os que compõem o PEDI.

TABELA 1: Atributos químicos e físicos nos pontos de coleta de amostras deformadas de solo nas profundidades 0-0,10 m; 0,10-0,30 m; e 0,30-0,60 m no Parque Estadual Dois Irmãos (PEDI) em Pernambuco, média e coeficiente de variação dos dados.

TABLE 1: Chemical and physical attributes at collection points of deformed samples of soil on depths $0-0.10$ $\mathrm{m}$; 0.10-0.30 m; and 0.30-0.60 m in State Park Dois Irmãos (PEDI) in Pernambuco state, mean and coefficient of variation of the data

\begin{tabular}{|c|c|c|c|c|c|c|c|c|c|c|c|c|c|c|}
\hline \multirow{4}{*}{ Atributo } & \multicolumn{12}{|c|}{ Ponto de coleta de solo } & \multirow{4}{*}{ Média } & \multirow{4}{*}{$\begin{array}{l}\text { CV } \\
(\%)\end{array}$} \\
\hline & 1 & 2 & 3 & 4 & 5 & 6 & 7 & 8 & 9 & 10 & 11 & 12 & & \\
\hline & \multicolumn{4}{|c|}{ Argissolo Amarelo } & \multicolumn{4}{|c|}{ Latossolo Amarelo } & \multicolumn{4}{|c|}{ Argissolo Amarelo } & & \\
\hline & \multicolumn{12}{|c|}{ Profundidade $0-0,10 \mathrm{~m}$} & & \\
\hline $\mathrm{pH}\left(\mathrm{H}_{2} \mathrm{O} 1: 2,5\right)$ & 4,13 & 4,10 & 3,97 & 3,84 & 4,13 & 4,12 & 4,45 & 4,34 & 4,29 & 3,93 & 4,14 & 4,38 & 4,15 & 4,5 \\
\hline $\mathrm{Ca}^{2+}\left(\mathrm{cmol}_{\mathrm{c}} \mathrm{dm}^{-3}\right)$ & 0,21 & 0,35 & 0,32 & 0,31 & 0,17 & 0,18 & 0,23 & 0,16 & 0,16 & 0,27 & 0,28 & 0,18 & 0,24 & 29,1 \\
\hline $\mathrm{Mg}^{2+}\left(\mathrm{cmol}_{\mathrm{c}} \mathrm{dm}^{-3}\right)$ & 0,10 & 0,17 & 0,22 & 0,18 & 0,27 & 0,13 & 0,12 & 0,14 & 0,42 & 0,15 & 0,03 & 0,16 & 0,18 & 55,0 \\
\hline $\mathrm{K}^{+}\left(\mathrm{cmol}_{\mathrm{c}} \mathrm{dm}^{-3}\right)$ & 0,14 & 0,06 & 0,05 & 0,06 & 0,09 & 0,06 & 0,06 & 0,04 & 0,09 & 0,04 & 0,02 & 0,11 & 0,07 & 49,1 \\
\hline $\mathrm{Na}\left(\mathrm{cmol}_{\mathrm{c}} \mathrm{dm}^{-3}\right)$ & 0,07 & 0,04 & 0,07 & 0,06 & 0,14 & 0,10 & 0,05 & 0,06 & 0,06 & 0,04 & 0,00 & 0,10 & 0,07 & 54,0 \\
\hline $\mathrm{Al}^{3+}\left(\mathrm{cmol}_{\mathrm{c}} \mathrm{dm}^{-3}\right)$ & 2,30 & 1,70 & 2,20 & 2,60 & 2,40 & 2,90 & 1,80 & 2,30 & 2,00 & 2,00 & 1,20 & 1,50 & 2,08 & 23,0 \\
\hline$(\mathrm{H}+\mathrm{Al})\left(\mathrm{cmol}_{\mathrm{c}} \mathrm{dm}^{-3}\right)$ & 6,76 & 5,94 & 9,24 & 9,73 & 11,55 & 13,03 & 5,77 & 7,92 & 11,88 & 7,75 & 4,12 & 5,11 & 8,23 & 34,9 \\
\hline $\mathrm{P}\left(\mathrm{mg} \mathrm{dm}^{-3}\right)$ & 3,35 & 2,08 & 2,50 & 0,52 & 1,30 & 2,50 & 1,65 & 1,02 & 2,36 & 2,29 & 3,42 & 2,22 & 2,10 & 41,2 \\
\hline $\mathrm{SB}\left(\mathrm{cmol}_{\mathrm{c}} \mathrm{dm}^{-3}\right)^{(\mathrm{SB})}$ & 1,41 & 0,62 & 0,66 & 0,61 & 0,67 & 0,47 & 0,46 & 0,40 & 0,73 & 0,50 & 0,33 & 0,55 & 0,62 & 44,8 \\
\hline $\mathrm{t}\left(\mathrm{cmol}_{\mathrm{c}} \mathrm{dm}^{-3}\right)^{(\mathrm{CTCE})}$ & 3,71 & 2,32 & 2,86 & 3,21 & 3,07 & 3,37 & 2,26 & 2,70 & 2,73 & 2,50 & 1,53 & 2,05 & 2,69 & 22,6 \\
\hline $\mathrm{T}\left(\mathrm{cmol}_{\mathrm{c}} \mathrm{dm}^{-3}\right)^{(\mathrm{CTCP})}$ & 8,17 & 6,56 & 9,90 & 10,34 & 12,22 & 13,50 & 6,23 & 8,32 & 12,61 & 8,25 & 4,45 & 5,66 & 8,85 & 32,9 \\
\hline
\end{tabular}


TABELA 1: Continuação...

TABLE 1: Continued...

\begin{tabular}{|c|c|c|c|c|c|c|c|c|c|c|c|c|c|c|}
\hline \multirow{4}{*}{ Atributo } & \multicolumn{12}{|c|}{ Ponto de coleta de solo } & \multirow{4}{*}{\multicolumn{2}{|c|}{$\begin{array}{l}\text { CV } \\
(\%)\end{array}$}} \\
\hline & 1 & 2 & 3 & 4 & 5 & 6 & 7 & 8 & 9 & 10 & 11 & 12 & & \\
\hline & \multicolumn{4}{|c|}{ Argissolo Amarelo } & \multicolumn{4}{|c|}{ Latossolo Amarelo } & \multicolumn{4}{|c|}{ Argissolo Amarelo } & & \\
\hline & \multicolumn{12}{|c|}{ Profundidade $0-0,10 \mathrm{~m}$} & & \\
\hline $\mathrm{V}(\%)^{(\mathrm{SPB})}$ & 17,25 & 9,45 & 6,66 & 5,89 & 5,48 & 3,48 & 7,38 & 4,80 & 5,78 & 6,06 & 7,41 & 9,71 & 7,45 & 47,8 \\
\hline $\mathrm{m}(\%)^{(\mathrm{SA})}$ & 61,99 & 73,27 & 76,92 & 80,99 & 77,17 & 86,05 & 79,20 & 85,18 & 73,26 & 80,00 & 78,43 & 73,17 & 77,14 & 8,3 \\
\hline Areia (\%) & 84,70 & 81,96 & 37,20 & 30,46 & 46,18 & 20,18 & 48,37 & 41,52 & 25,20 & 65,17 & 75,82 & 63,61 & 51,70 & 42,9 \\
\hline Silte (\%) & 3,68 & 4,48 & 9,74 & 2,42 & 1,88 & 18,94 & 9,89 & 9,30 & 10,37 & 8,56 & 6,23 & 10,67 & 8,01 & 58,8 \\
\hline Argila (\%) & 11,62 & 13,56 & 53,06 & 67,12 & 51,94 & 60,88 & 41,74 & 49,18 & 64,43 & 26,27 & 17,95 & 25,72 & 40,29 & 50,5 \\
\hline $\operatorname{Dp}\left(\mathrm{g} \mathrm{cm}^{-3}\right)$ & 2,70 & 2,66 & 2,59 & 2,56 & 2,53 & 2,56 & 2,56 & 2,59 & 2,66 & 2,59 & 2,77 & 2,63 & 2,62 & 2,7 \\
\hline \multicolumn{15}{|c|}{ Profundidade $0,10-0,30 \mathrm{~m}$} \\
\hline $\mathrm{pH}\left(\mathrm{H}_{2} \mathrm{O} 1: 2,5\right)$ & 4,13 & 4,22 & 3,83 & 4,25 & 4,06 & 4,34 & 4,16 & 4,16 & 3,90 & 4,36 & 4,35 & 4,50 & 4,19 & 4,6 \\
\hline $\mathrm{Ca}^{2+}\left(\mathrm{cmol}_{\mathrm{c}} \mathrm{dm}^{-3}\right)$ & 0,16 & 0,25 & 0,19 & 0,13 & 0,05 & 0,05 & 0,06 & 0,06 & 0,30 & 0,16 & 0,16 & 0,13 & 0,14 & 56,5 \\
\hline $\mathrm{Mg}^{2+}\left(\mathrm{cmol}_{\mathrm{c}} \mathrm{dm}^{-3}\right)$ & 0,16 & 0,19 & 0,19 & 0,19 & 0,12 & 0,11 & 0,12 & 0,12 & 0,13 & 0,11 & 0,04 & 0,04 & 0,13 & 40,4 \\
\hline $\mathrm{K}^{+}\left(\mathrm{cmol}_{\mathrm{c}} \mathrm{dm}^{-3}\right)$ & 0,04 & 0,05 & 0,02 & 0,05 & 0,04 & 0,04 & 0,03 & 0,06 & 0,04 & 0,03 & 0,03 & 0,04 & 0,04 & 27,7 \\
\hline $\mathrm{Na}\left(\mathrm{cmol}_{\mathrm{c}} \mathrm{dm}^{-3}\right)$ & 0,02 & 0,03 & 0,04 & 0,04 & 0,06 & 0,09 & 0,03 & 0,05 & 0,03 & 0,03 & 0,02 & 0,06 & 0,04 & 48,9 \\
\hline $\mathrm{Al}^{3+}\left(\mathrm{cmol}_{\mathrm{c}} \mathrm{dm}^{-3}\right)$ & 2,10 & 1,20 & 1,80 & 2,10 & 2,00 & 2,30 & 1,70 & 2,00 & 2,00 & 1,80 & 1,50 & 1,50 & 1,83 & 17,1 \\
\hline$(\mathrm{H}+\mathrm{Al})\left(\mathrm{cmol}_{\mathrm{c}} \mathrm{dm}^{-3}\right)$ & 7,42 & 2,31 & 4,78 & 7,42 & 5,94 & 9,57 & 6,27 & 5,94 & 6,10 & 5,44 & 4,78 & 6,62 & 6,05 & 29,1 \\
\hline $\left.\mathrm{P}(\mathrm{mg} \mathrm{dm})^{-3}\right)$ & 2,36 & 1,72 & 3,49 & 1,23 & 1,59 & 2,64 & 1,44 & 0,88 & 1,51 & 1,94 & 3,35 & 1,87 & 2,00 & 40,6 \\
\hline $\mathrm{SB}\left(\mathrm{cmolc}_{\mathrm{c}} \mathrm{dm}^{-3}\right)^{(\mathrm{SB})}$ & 0,38 & 0,52 & 0,47 & 0,44 & 0,27 & 0,29 & 0,24 & 0,29 & 0,50 & 0,33 & 0,25 & 0,27 & 0,35 & 29,1 \\
\hline $\mathrm{t}\left(\mathrm{cmol}_{\mathrm{c}} \mathrm{dm}^{-3}\right)^{(\mathrm{CTCE})}$ & 2,48 & 1,72 & 2,27 & 2,54 & 2,27 & 2,59 & 1,94 & 2,29 & 2,50 & 2,13 & 1,75 & 1,77 & 2,19 & 14,7 \\
\hline $\mathrm{T}\left(\mathrm{cmol}_{\mathrm{c}} \mathrm{dm}^{-3}\right)^{(\mathrm{CTCP})}$ & 7,80 & 2,83 & 5,25 & 7,86 & 6,21 & 9,86 & 6,51 & 6,23 & 6,60 & 5,77 & 5,03 & 6,89 & 6,40 & 27,0 \\
\hline $\mathrm{V}(\%)^{(\mathrm{SPB})}$ & 4,87 & 18,37 & 8,95 & 5,59 & 4,34 & 2,94 & 3,68 & 4,65 & 7,57 & 5,71 & 4,97 & 3,91 & 6,30 & 65,9 \\
\hline $\mathrm{m}(\%)^{(\mathrm{SA})}$ & 84,67 & 69,76 & 79,29 & 82,67 & 88,10 & 88,80 & 87,62 & 87,33 & 80,00 & 84,50 & 85,71 & 84,74 & 83,19 & 6,4 \\
\hline Areia (\%) & 61,11 & 86,23 & 37,14 & 29,87 & 28,09 & 18,68 & 40,62 & 41,11 & 29,14 & 63,01 & 73,43 & 64,26 & 47,72 & 44,4 \\
\hline Silte (\%) & 13,80 & 4,86 & 14,38 & 2,87 & 8,90 & 20,22 & 9,75 & 10,28 & 7,00 & 12,19 & 6,62 & 4,02 & 9,57 & 52,3 \\
\hline Argila (\%) & 25,09 & 8,91 & 48,48 & 67,26 & 63,01 & 61,10 & 49,63 & 48,61 & 63,86 & 24,80 & 19,95 & 31,72 & 42,70 & 46,5 \\
\hline $\mathrm{Dp}\left(\mathrm{g} \mathrm{cm}^{-3}\right)$ & 2,63 & 2,73 & 2,66 & 2,59 & 2,50 & 2,53 & 2,63 & 2,56 & 2,04 & 2,66 & 2,70 & 2,66 & 2,62 & 2,6 \\
\hline \multicolumn{15}{|c|}{ Profundidade $0,30-0,60 \mathrm{~m}$} \\
\hline $\mathrm{H}_{2}\left(\mathrm{H}_{2} \mathrm{O}_{1} \cdot 25\right)$ & 4,61 & 4,10 & 3,71 & 4,24 & 4,34 & 4,53 & 4,49 & 4,12 & 4,06 & 4,76 & 4,56 & 4,76 & 4,36 & 7,3 \\
\hline $\mathrm{Ca}^{2+}\left(\mathrm{cmol}_{\mathrm{c}} \mathrm{dm}^{-3}\right)$ & 0,12 & 0,12 & 0,06 & 0,07 & 0,03 & 0,05 & 0,04 & 0,05 & 0,13 & 0,05 & 0,09 & 0,05 & 0,07 & 48,3 \\
\hline $\mathrm{Mg}^{2+}\left(\mathrm{cmol}_{\mathrm{c}} \mathrm{dm}^{-3}\right)$ & 0,09 & 0,08 & 0,18 & 0,03 & 0,11 & 0,13 & 0,06 & 0,07 & 0,08 & 0,02 & 0,02 & 0,02 & 0,07 & 66,7 \\
\hline $\mathrm{K}^{+}\left(\mathrm{cmol}_{\mathrm{c}} \mathrm{dm}^{-3}\right)$ & 0,12 & 0,17 & 0,11 & 0,02 & 0,09 & 0,02 & 0,02 & 0,02 & 0,04 & 0,02 & 0,01 & 0,01 & 0,05 & 99,7 \\
\hline $\mathrm{Na}\left(\mathrm{cmol}_{\mathrm{c}} \mathrm{dm}^{-3}\right)$ & 0,03 & 0,07 & 0,08 & 0,03 & 0,02 & 0,04 & 0,03 & 0,03 & 0,07 & 0,01 & 0,04 & 0,01 & 0,04 & 60,8 \\
\hline $\mathrm{Al}^{3+}\left(\mathrm{cmol}_{\mathrm{c}} \mathrm{dm}^{-3}\right)$ & 1,30 & 1,20 & 1,20 & 1,30 & 1,30 & 1,40 & 1,20 & 1,50 & 1,40 & 1,20 & 1,10 & 1,20 & 1,28 & 8,9 \\
\hline$(\mathrm{H}+\mathrm{Al})\left(\mathrm{cmol}_{\mathrm{c}} \mathrm{dm}^{-3}\right)$ & 3,96 & 2,64 & 2,80 & 2,80 & 3,79 & 5,77 & 3,63 & 4,29 & 3,46 & 3,79 & 8,25 & 3,96 & 4,10 & 37,8 \\
\hline $\mathrm{P}\left(\mathrm{mg} \mathrm{dm} \mathrm{m}^{-3}\right)$ & 1,09 & 1,23 & 1,16 & 1,09 & 0,74 & 1,51 & 1,09 & 0,59 & 1,16 & 2,43 & 2,29 & 2,43 & 1,40 & 45,4 \\
\hline $\mathrm{SB}\left(\mathrm{cmol}_{\mathrm{c}} \mathrm{dm}^{-3}\right)^{(\mathrm{SB})}$ & 0,36 & 0,44 & 0,43 & 0,15 & 0,25 & 0,24 & 0,15 & 0,17 & 0,32 & 0,10 & 0,13 & 0,09 & 0,24 & 53,0 \\
\hline $\mathrm{t}\left(\mathrm{cmol}_{\mathrm{c}} \mathrm{dm}^{-3}\right)^{(\mathrm{CTCE})}$ & 1,66 & 1,64 & 1,63 & 1,45 & 1,55 & 1,64 & 1,35 & 1,67 & 1,72 & 1,30 & 1,23 & 1,29 & 1,51 & 11,7 \\
\hline $\mathrm{T}\left(\mathrm{cmol}_{\mathrm{c}} \mathrm{dm}^{-3}\right)^{(\mathrm{CTCP})}$ & 4,32 & 3,08 & 3,23 & 2,95 & 4,04 & 6,01 & 3,78 & 4,46 & 3,78 & 3,89 & 8,38 & 4,05 & 4,33 & 34,7 \\
\hline$V(\%)^{(\mathrm{SPB})}$ & 8,33 & 14,28 & 13,31 & 5,08 & 6,18 & 3,99 & 3,96 & 3,81 & 8,46 & 2,57 & 1,55 & 2,22 & 6,15 & 68,2 \\
\hline $\mathrm{m}(\%)^{(\mathrm{SA})}$ & 77,31 & 73,17 & 73,61 & 89,65 & 83,87 & 85,36 & 88,88 & 89,82 & 81,39 & 92,30 & 89,43 & 93,02 & 84,82 & 8,3 \\
\hline Areia (\%) & 51,04 & 77,39 & 35,43 & 25,77 & 24,30 & 17,23 & 42,62 & 36,38 & 22,06 & 57,43 & 66,92 & 61,49 & 43,17 & 45,4 \\
\hline Silte (\%) & 14,24 & 5,18 & 10,01 & 4,86 & 9,62 & 3,67 & 5,68 & 10,91 & 12,05 & 11,17 & 10,16 & 25,02 & 10,21 & 55,9 \\
\hline Argila (\%) & 34,72 & 17,43 & 54,56 & 69,37 & 66,08 & 79,10 & 51,70 & 52,71 & 65,89 & 31,40 & 22,92 & 13,49 & 46,61 & 47,2 \\
\hline $\operatorname{Dp}\left(\mathrm{g} \mathrm{cm}^{-3}\right)$ & 2,66 & 2,53 & 2,66 & 2,70 & 2,59 & 2,46 & 2,70 & 2,66 & 2,85 & 2,81 & 2,63 & 2,66 & 2,66 & 4,0 \\
\hline
\end{tabular}

Em que: $\mathrm{SB}=$ Soma de bases; $\mathrm{CTCE}=$ Capacidade de troca de cátions efetiva do solo; $\mathrm{CTCP}=$ Capacidade de troca de cátions a pH 7 do solo; SPB = Saturação por bases; SA = Saturação por alumínio.

De maneira geral, todos os cátions básicos foram avaliados como apresentando teores muitos baixos nos solos do PEDI. É conveniente salientar, entretanto, que essas são classificações obtidas em estudos realizados em solos agrícolas, cujo comportamento é bem diferente dos solos florestais. Os níveis críticos mencionados são obtidos para elevadas produções agrícolas, quase no pico da produção máxima de determinadas culturas em sistemas convencionais de cultivo. É provável que níveis críticos de cátions básicos trocáveis em solos florestais sejam bem menores que estes apresentados por esses autores, o que explicaria a exuberância das espécies florestais do PEDI. Em consonância com isso, a ciclagem de nutrientes também responde por uma parcela considerável da nutrição florestal, principalmente em sistemas em equilíbrio natural. Portanto, não é muito conveniente afirmar que sob florestas tropicais exuberantes, existem solos pobres nutricionalmente, porque os critérios utilizados para avaliar os solos florestais não são os mais adequados e podem levar a conclusões equivocadas.

É importante que se possam desenvolver estudos mais elucidativos que relacionem teores de 
nutrientes em solos florestais com a nutrição de espécies nativas em equilíbrio, gerando informações sobre o comportamento da dinâmica destes nutrientes no solo, porém, dentro de sua própria lógica, de seu próprio ambiente. Conclusões de estudos como este podem surpreender, porque certamente irão diferir do sistema agrícola convencional de elevadas produtividades. Os solos florestais têm sua própria capacidade produtiva, bem como teores de nutrientes em equilíbrio harmônico no ecossistema, exercendo sua função na ciclagem nutricional.

Os baixos teores de $\mathrm{Ca}^{2+}, \mathrm{Mg}^{2+}, \mathrm{K}^{+}$e $\mathrm{Na}^{+}$foram responsáveis pela baixa saturação por bases $(\mathrm{V})$ do complexo de troca dos solos (Tabela 1). De maneira geral, para a maioria das culturas agrícolas, o nível crítico desejado para a saturação por bases é de 60\% (ALVAREZ et al., 1999), desse modo, os resultados encontrados neste trabalho representam, em média, $11 \%$ deste valor. Todos os valores de saturação por bases dos solos do PEDI não ultrapassaram a classe muito baixa, parametrizada como sendo de 20\% (ALVAREZ et al., 1999).

Além da elevada acidez ativa $(\mathrm{pH})$, verificou-se que os solos apresentaram elevada acidez trocável, representada pelo cátion de caráter ácido predominante nos solos, o $\mathrm{Al}^{3+}$ (Tabela 1). Em todas as camadas dos solos, o teor de $\mathrm{Al}^{3+}$ superou a classe de média disponibilidade, de $0,51 \mathrm{a} 1,00 \mathrm{cmol}_{\mathrm{c}}$ $\mathrm{dm}^{-3}$, com $75 \%$ e $25 \%$ das amostras enquadrando-se nas classes alta e muito alta, respectivamente (ALVAREZ et al., 1999).

Valores elevados da acidez trocável do solo são prejudiciais ao desenvolvimento das plantas, inclusive de espécies florestais, pelo efeito tóxico do $\mathrm{Al}^{3+}$ em elevadas concentrações (CITADINI-ZANETTE, 1995; BOTREL et al., 2002; DALANESI; OLIVEIRA FILHO; FONTES, 2004; CARVALHO et al., 2005; ROSSI et al., 2005; RUGGIERO et al., 2006; MAFRA et al., 2008; SILVA et al., 2015). Entretanto, em solos florestais, parte dos teores de $\mathrm{Al}^{3+}$ são normalmente quelatizados por substâncias húmicas decorrentes da decomposição da matéria orgânica, o que minimiza sua ação tóxica (HARTWIG et al., 2007).

Após a sua absorção pelas plantas, $\mathrm{o} \mathrm{Al}^{3+}$ impede a divisão celular, restringindo o crescimento dos tecidos vegetais, de modo especial das raízes, limitando assim, o acesso à água e nutrientes (GAMA; KIEHL, 1999). Além dessas limitações, elevadas concentrações de $\mathrm{Al}^{3+}$ no solo, associadas a baixos teores de $\mathrm{Ca}^{2+}$ podem formar uma barreira química impedindo o crescimento vertical de raízes (FERREIRA et al., 2007; DANTAS et al., 2014; CORRÊA et al., 2015), reduzindo consideravelmente a sustentabilidade das árvores, favorecendo o seu tombamento. Isso pode se relacionar com quedas frequentes de árvores em fragmentos florestais sobre solos muito ácidos, como os do PEDI. Neste parque, há relatos de frequentes tombamentos de árvores, o que pode estar associado às elevadas concentrações de $\mathrm{Al}^{3+} \mathrm{e}$ baixos teores de $\mathrm{Ca}^{2+}$ encontrados até $0,60 \mathrm{~m}$ de profundidade (Tabela 1)

Os baixos valores de saturação por bases e os elevados teores de $\mathrm{Al}^{3+}$, nas diferentes camadas dos solos, levaram a uma alta saturação do complexo de troca por $\mathrm{Al}^{3+}(\mathrm{m})$ (Tabela 1). Essa saturação aumentou com a profundidade, variando de $62 \%$ a $86 \%$, de $70 \%$ a $89 \%$ e de $73 \%$ a $93 \%$, nas camadas de $0,0-0,10$, de 0,10-0,30 e de 0,30-0,60 m. Os valores encontrados neste trabalho são considerados tóxicos para a maioria das culturas, ultrapassando em muito o limite de $30 \%$ indicado para a adoção da gessagem, para ação em subsuperfície (ALVAREZ et al., 1999). É provável que esteja ocorrendo uma considerável quelatização deste $\mathrm{Al}^{3+}$ pelos ácidos orgânicos produzidos pela matéria orgânica nos solos do PEDI, pela ausência de sintomas nas árvores de toxidez de Al. Entretanto, é também provável que esteja se formando uma barreira química pelos elevados teores de $\mathrm{Al}^{3+}$, que provoque o tombamento de árvores sadias no Parque. Para a realização deste estudo foi constatada a queda de 52 árvores de diferentes espécies nas principais trilhas do PEDI.

De maneira geral, assim como a acidez trocável, a acidez potencial decresceu com a profundidade, de 8,23 a $4,10 \mathrm{cmol}_{\mathrm{c}} \mathrm{dm}^{-3}$, em média (Tabela 1). É provável que a grande quantidade de matéria orgânica que apresentam os solos florestais, ao mineralizar, estejam liberando uma quantidade significativa de $\mathrm{H}^{+}$, elevando a acidez ativa e sendo responsável pela elevação também da acidez potencial.

Com uma única exceção, os teores de $(\mathrm{H}+\mathrm{Al})$ se situaram nas classes: média, alta e muito alta (Tabela 1). Nas duas camadas superficiais houve um maior número de amostras nas classes alta e muito alta, sendo $92 \%$ e $75 \%$ nas camadas de $0,0-0,10 \mathrm{~m}$ e de $0,10-0,30 \mathrm{~m}$. Enquanto $82 \%$ das amostras da camada mais profunda se enquadraram na classe média.

Em solos florestais, como no fragmento estudado, existe uma grande concentração na manta

Ci. Fl., v. 28, n. 2, abr. - jun., 2018 
orgânica de $\mathrm{Ca}^{2+}, \mathrm{Mg}^{2+}$ e $\mathrm{K}^{+}$e pequena no solo, principalmente em profundidade (ESPIG et al., 2009), favorecendo a concentração de (H+Al) na parte subsuperficial do solo (MARIN, 2002). Em discordância com o referido autor, as amostras analisadas tiveram seus teores de acidez potencial minimizados em profundidade (Tabela 1). Mesmo assim, essa acidez potencial apresentou-se elevada, devido a extrema acidez ativa da área estudada.

Os teores de P disponível nas camadas dos solos não ultrapassaram o valor de $3,50 \mathrm{mg} \mathrm{dm}^{-3}$, sendo considerados baixos ou muito baixos (ALVAREZ et al., 1999), e como os demais nutrientes, decresceram em profundidade. A baixa disponibilidade de $\mathrm{P}$ em ambientes tropicais é um dos fatores limitantes para o crescimento de espécies florestais (JORDAN, 1991; CITADINI-ZANETTE, 1995), contudo a produção vegetal sobre os solos do PEDI, aparentemente, não se apresenta limitada.

No caso específico do $\mathrm{P}$ e em ambientes florestais, pode ocorrer absorção direta do P da manta orgânica, à medida que ocorre a mineralização da matéria orgânica (NOVAIS; SMYTH, 1999; ESPIG et al., 2009). É provável que esses baixos teores disponíveis de $P$ em solos florestais tenham um efeito mais severo no processo de regeneração, deixando as espécies mais dependentes da mineralização da matéria orgânica. Em solos tropicais em que os processos de adsorção de P se intensificam (NOVAIS; SMYTH, 1999), essa dependência pode ser ainda mais danosa à regeneração.

Todos os nutrientes avaliados, nas diferentes camadas dos solos, estiveram abaixo do nível crítico para a maioria das culturas agrícolas, ou seja, não seriam capazes de promover elevada produção de fitomassa. Entretanto, a vegetação natural se apresenta exuberante, como a do PEDI.

Em ecossistemas naturais não perturbados diretamente pelo homem, a existência de vários processos químicos e biológicos permite que as plantas, mesmo em condições de baixa disponibilidade de elementos essenciais ao seu desenvolvimento, os utilizem de forma eficiente (NOVAIS; SMYTH, 1999).

As plantas desenvolvem mecanismos especiais para absorverem nutrientes quando seus teores disponíveis são baixos. O mais importante é o desenvolvimento de raízes finas na superfície do solo, penetrando a manta orgânica e absorvendo os nutrientes recém mineralizados. Espig et al. (2009) estudando fragmento florestal da Mata Atlântica em Pernambuco, afirmaram que os teores de nutrientes quantificados na manta orgânica justificam a exuberância de um fragmento florestal sobre um solo de baixa fertilidade. Os autores argumentaram ainda que a nutrição do fragmento independe dos teores das bases trocáveis $\left(\mathrm{Ca}^{2+}\right.$, $\mathrm{Mg}^{2+}$ e $\mathrm{K}^{+}$) do solo, devido ao grande aporte de nutrientes via serrapilheira.

A análise granulométrica das amostras mostrou que há variações na classe textural dos solos do PEDI, de arenosa até muito argilosa, constatando-se o predomínio das classes texturais argila e muito argilosa, representando cerca de $25 \%$ e de $31 \%$ das amostras, respectivamente (Tabela 1). Portanto, são solos capazes de exercer uma sustentação mais efetiva das árvores, do que se fossem solos mais arenosos.

Contrariamente, o que tem se observado no PEDI é uma frequente queda de árvores. Isto corrobora a tese de que parece ser muito mais um efeito químico que físico, pelos elevados teores de $\mathrm{Al}^{3+}$, causando uma provável barreira química, impedindo o crescimento das raízes.

A densidade de partículas dos solos do PEDI variaram pouco em relação à média, concentrandose em torno de 2,62, de 2,62 e de 2,66 $\mathrm{g} \mathrm{cm}^{-3}$, da camada superficial até a mais profunda (Tabela 1). Essa é um atributo físico de pouca variabilidade, porque é dependente de minerais primários de formação dos solos, que não variam muito entre Argissolos e Latossolos.

Os valores de densidade do solo variaram nos solos do PEDI, de 1,04 a $1,51 \mathrm{~g} \mathrm{~cm}^{-3}$ e de 1,10 a $1,54 \mathrm{~g} \mathrm{~cm}^{-3}$ na camada de 0,0-0,05 $\mathrm{m}$ e de 0,10-0,15 m respectivamente, sendo a média da camada subsuperficial mais alta (Tabela 2). É de se esperar que a camada superficial apresente maior concentração de matéria orgânica, reduzindo a densidade do solo. Entretanto, nenhuma das amostras apresentou valor superior a $1,75 \mathrm{~g} \mathrm{~cm}^{-3}$, que para Collares et al. (2006) pode ser considerado o limite crítico, ou seja, camadas com densidade de solo acima desse valor restringe o crescimento das raízes. Esse atributo físico, assim como a granulometria, favorece a sustentação das árvores do PEDI, o que não tem ocorrido enfatizando mais uma vez a explicação de que o tombamento das árvores parece ser um processo mais químico, do que físico.

A porosidade total dos solos apresentou-se pouco variável entre as diferentes camadas, tendo sido $10 \%$ maior na camada superficial (Tabela 2). Os menores valores de porosidade total encontrados na camada subsuperficial podem ser atribuídos à menor concentração de matéria orgânica, corroborando a hipótese

Ci. Fl., v. 28, n. 2, abr. - jun., 2018 
levantada anteriormente. Contudo, as porosidades que compõem a porosidade total (macro, meso, micro e criptoporosidade) apresentaram elevada variação entre os locais e as camadas coletadas, chegando a ser de $78 \%$ no volume de mesoporos em subsuperficie (Tabela 2 ).

TABELA 2: Atributos físicos nos pontos de coleta de amostras não deformadas do solo nas profundidades 0-0,05 m e 0,10-0,15 m no Parque Estadual Dois Irmãos (PEDI) em Pernambuco, média e coeficiente de variação dos dados.

TABLE 2: Physical attributes at collection points of not deformed samples of soil on depths $0-0.05 \mathrm{~m}$ and $0.10-0.15 \mathrm{~m}$ in the State Park Dois Irmãos (PEDI) in Pernambuco state, mean and coefficient of variation of the data.

\begin{tabular}{|c|c|c|c|c|c|c|c|c|c|c|c|c|c|c|}
\hline \multirow{4}{*}{ Atributo } & \multicolumn{12}{|c|}{ Ponto de coleta de solo } & \multirow{4}{*}{ Média } & \multirow{4}{*}{$\begin{array}{l}\text { CV } \\
(\%)\end{array}$} \\
\hline & 1 & 2 & 3 & 4 & 5 & 6 & 7 & 8 & 9 & 10 & 11 & 12 & & \\
\hline & \multicolumn{4}{|c|}{ Argissolo Amarelo } & \multicolumn{4}{|c|}{ Latossolo Amarelo } & \multicolumn{4}{|c|}{ Argissolo Amarelo } & & \\
\hline & \multicolumn{12}{|c|}{ Profundidade $0-0,05 \mathrm{~m}$} & & \\
\hline $\mathrm{DS}\left(\mathrm{g} \mathrm{cm}^{-3}\right)$ & 1,29 & 1,25 & 1,42 & 1,18 & 1,11 & 1,04 & 1,31 & 1,51 & 1,17 & 1,44 & 1,29 & 1,27 & 1,27 & 10,81 \\
\hline $\operatorname{MAP}\left(\mathrm{cm}^{3} \mathrm{~cm}^{-3}\right)$ & 0,05 & 0,08 & 0,04 & 0,13 & 0,09 & 0,10 & 0,04 & 0,05 & 0,05 & 0,04 & 0,04 & 0,06 & 0,06 & 45,78 \\
\hline $\operatorname{MEP}\left(\mathrm{cm}^{3} \mathrm{~cm}^{-3}\right)$ & 0,20 & 0,25 & 0,11 & 0,10 & 0,08 & 0,08 & 0,06 & 0,02 & 0,07 & 0,09 & 0,21 & 0,14 & 0,12 & 58,75 \\
\hline $\operatorname{MIP}\left(\mathrm{cm}^{3} \mathrm{~cm}^{-3}\right)$ & 0,04 & 0,03 & 0,08 & 0,07 & 0,07 & 0,06 & 0,09 & 0,09 & 0,09 & 0,06 & 0,10 & 0,08 & 0,07 & 29,65 \\
\hline $\mathrm{CP}\left(\mathrm{cm}^{3} \mathrm{~cm}^{-3}\right)$ & 0,07 & 0,05 & 0,14 & 0,21 & 0,22 & 0,27 & 0,22 & 0,24 & 0,26 & 0,18 & 0,11 & 0,15 & 0,18 & 41,27 \\
\hline PT $\left(\mathrm{cm}^{3} \mathrm{~cm}^{-3}\right)$ & 0,36 & 0,41 & 0,37 & 0,51 & 0,46 & 0,51 & 0,41 & 0,40 & 0,47 & 0,37 & 0,46 & 0,43 & 0,43 & 12,14 \\
\hline $\mathrm{CC}\left(\mathrm{cm}^{3} \mathrm{~cm}^{-3}\right)$ & 0,10 & 0,06 & 0,19 & 0,23 & 0,26 & 0,32 & 0,26 & 0,28 & 0,32 & 0,22 & 0,13 & 0,20 & 0,21 & 38,78 \\
\hline $\operatorname{PMP}\left(\mathrm{cm}^{3} \mathrm{~cm}^{-3}\right)$ & 0,07 & 0,05 & 0,14 & 0,21 & 0,22 & 0,27 & 0,22 & 0,24 & 0,26 & 0,18 & 0,11 & 0,15 & 0,18 & 41,27 \\
\hline $\mathrm{CH}\left(\mathrm{cm} \mathrm{h}^{-1}\right)$ & 114 & 269 & 3 & 10 & 5 & 22 & 3 & 1 & 14 & 3 & 91 & 32 & 47 & 167 \\
\hline $\mathrm{AD}\left(\mathrm{cm}^{3} \mathrm{~cm}^{-3}\right)$ & 0,03 & 0,01 & 0,05 & 0,03 & 0,04 & 0,05 & 0,04 & 0,04 & 0,06 & 0,04 & 0,02 & 0,04 & 0,04 & 36,18 \\
\hline \multicolumn{15}{|c|}{ Profundidade $0,10-0,15 \mathrm{~m}$} \\
\hline Ds $\left(\mathrm{g} \mathrm{cm}^{-3}\right)$ & 1,33 & 1,24 & 1,40 & 1,25 & 1,22 & 1,10 & 1,54 & 1,51 & 1,31 & 1,49 & 1,42 & 1,28 & 1,34 & 9,96 \\
\hline $\operatorname{MAP}\left(\mathrm{cm}^{3} \mathrm{~cm}^{-3}\right)$ & 0,06 & 0,04 & 0,04 & 0,08 & 0,04 & 0,04 & 0,05 & 0,07 & 0,04 & 0,04 & 0,04 & 0,08 & 0,05 & 31,79 \\
\hline $\operatorname{MEP}\left(\mathrm{cm}^{3} \mathrm{~cm}^{-3}\right)$ & 0,12 & 0,22 & 0,04 & 0,07 & 0,05 & 0,05 & 0,02 & 0,05 & 0,04 & 0,08 & 0,18 & 0,04 & 0,08 & 77,61 \\
\hline $\operatorname{MIP}\left(\mathrm{cm}^{3} \mathrm{~cm}^{-3}\right)$ & 0,08 & 0,05 & 0,11 & 0,07 & 0,07 & 0,08 & 0,13 & 0,10 & 0,06 & 0,08 & 0,12 & 0,09 & 0,09 & 27,98 \\
\hline $\mathrm{CP}\left(\mathrm{cm}^{3} \mathrm{~cm}^{-3}\right)$ & 0,13 & 0,04 & 0,17 & 0,21 & 0,23 & 0,30 & 0,22 & 0,17 & 0,23 & 0,13 & 0,06 & 0,17 & 0,17 & 43,15 \\
\hline PT $\left(\mathrm{cm}^{3} \mathrm{~cm}^{-3}\right)$ & 0,39 & 0,35 & 0,36 & 0,43 & 0,39 & 0,47 & 0,42 & 0,39 & 0,37 & 0,33 & 0,40 & 0,38 & 0,39 & 9,66 \\
\hline $\mathrm{CC}\left(\mathrm{cm}^{3} \mathrm{~cm}^{-3}\right)$ & 0,17 & 0,06 & 0,22 & 0,23 & 0,26 & 0,36 & 0,25 & 0,20 & 0,30 & 0,17 & 0,09 & 0,25 & 0,21 & 39,18 \\
\hline $\operatorname{PMP}\left(\mathrm{cm}^{3} \mathrm{~cm}^{-3}\right)$ & 0,13 & 0,04 & 0,17 & 0,21 & 0,23 & 0,30 & 0,22 & 0,17 & 0,23 & 0,13 & 0,06 & 0,17 & 0,17 & 43,15 \\
\hline $\mathrm{CH}\left(\mathrm{cm} \mathrm{h}^{-1}\right)$ & 20 & 264 & 7 & 8 & 5 & 2 & 1 & 3 & 2 & 5 & 56 & 115 & 40 & 194 \\
\hline $\mathrm{AD}\left(\mathrm{cm}^{3} \mathrm{~cm}^{-3}\right)$ & 0,04 & 0,02 & 0,05 & 0,02 & 0,03 & 0,06 & 0,04 & 0,03 & 0,07 & 0,04 & 0,03 & 0,08 & 0,04 & 45,01 \\
\hline
\end{tabular}

Em que: $\mathrm{DS}=$ Densidade do solo $\mathrm{MAP}=$ Macroporos; $\mathrm{MEP}=$ Mesoporos; $\mathrm{MIP}=$ Microporos; $\mathrm{CP}=$ Criptoporos; $\mathrm{PT}=$ Porosidade total $; \mathrm{CC}=$ Capacidade de campo $\mathrm{PMP}=$ Ponto de murcha permanente $\mathrm{CH}=$ Condutividade Hidráulica saturada (Ksat); $\mathrm{AD}=$ Água disponível.

Entre as porosidades, a criptoporosidade se mostrou predominante nas duas camadas, com valor médio de 0,18 e $0,17 \mathrm{~cm}^{3} \mathrm{~cm}^{-3}$, da camada superficial até a subsuperficial, com variação de $40 \%$, em média (Tabela 2). Junto com a criptoporosidade, a microporosidade adsorve mais fortemente a água do solo. Assim, em ambas as camadas, o volume de água que poder ser adsorvido pela porosidade ultrapassa $50 \%$, sendo de $58 \%$ e de $67 \%$, na camada de $0,0-0,05 \mathrm{~m}$ e de 0,05 a $0,10 \mathrm{~m}$, respectivamente (Tabela 2). Deste modo, cerca de $42 \%$ e de $33 \%$ da porosidade total, da camada superficial a subsuperficial, foi composta por poros de redistribuição de água. Solos muito intemperizados como os do PEDI, em que se comprovaram elevados teores de $\mathrm{Al}^{3+}$ (Tabela 1), a agregação proporcionada pelos coloides argilosos permite que os solos sejam muito permeáveis ao movimento vertical e lateral de água, além da capacidade de agregação da matéria orgânica. Mesmo em solos argilosos e muito argilosos a distribuição de poros foi favorável à permeabilidade da água, evidenciando o efeito da predominância de cátions de elevada valência, como o $\mathrm{Al}^{3+}$ e a presença de matéria de orgânica.

A condutividade hidráulica saturada apresentou elevada variação entre os locais avaliados, sendo de $167 \%$ e de $194 \%$, nas camadas subsuperficial e superficial (Tabela 2). É provável que diferenças na concentração de matéria orgânica e de argila, na porosidade e na densidade do solo nos locais coletados, tenham levado a grande amplitude entre os dados. Deste modo, se torna possível associar os elevados valores de condutividade hidráulica saturada com as altas concentrações de areia nos pontos 1 e 2 da camada superficial e 11 e 12 da camada subsuperficial do Argissolo Amarelo (Tabelas 1 e 2). 
A água disponível nas camadas, em média, foi semelhante, tendo sido de $0,04 \mathrm{~cm}^{3} \mathrm{~cm}^{-3}$ (Tabela 2). Embora as variações entre os locais de coleta tenham sido altas em ambas as camadas, foi maior na subsuperficial. A quantidade de água disponível no solo do PEDI sofreu influência da granulometria, estrutura, porosidade e da declividade do terreno. Deste modo, a variação ocorrida em água disponível entre os locais de coleta foi devido à variabilidade dos atributos físicos mencionados.

A curva de retenção de água na profundidade 0,0-0,05 m, nos dois tipos de solo, apresentou queda abrupta de umidade com o aumento gradativo das tensões, até a tensão de $3 \mathrm{kPa}$, permanecendo constante até $1.500 \mathrm{kPa}$. Entretanto, a estabilidade do conteúdo de água no Latossolo Amarelo foi alcançada em maiores tensões, com 33,3 kPa (Figura 2A)

A curva de retenção de água das amostras na profundidade $0,10-0,15 \mathrm{~m}$ apresentou decréscimo gradativo com o aumento das tensões (Figura 2B). A retenção de água do Argissolo foi maior do que a do Latossolo até a tensão de $15 \mathrm{kPa}$. A partir dessa tensão há uma inversão, em que o Latossolo retém mais água do que o Argissolo, mantendo-se até $1.500 \mathrm{kPa}$. Contudo, em quantidades absolutas, o Argissolo reteve mais água (Figura $2 \mathrm{~B}$ ).

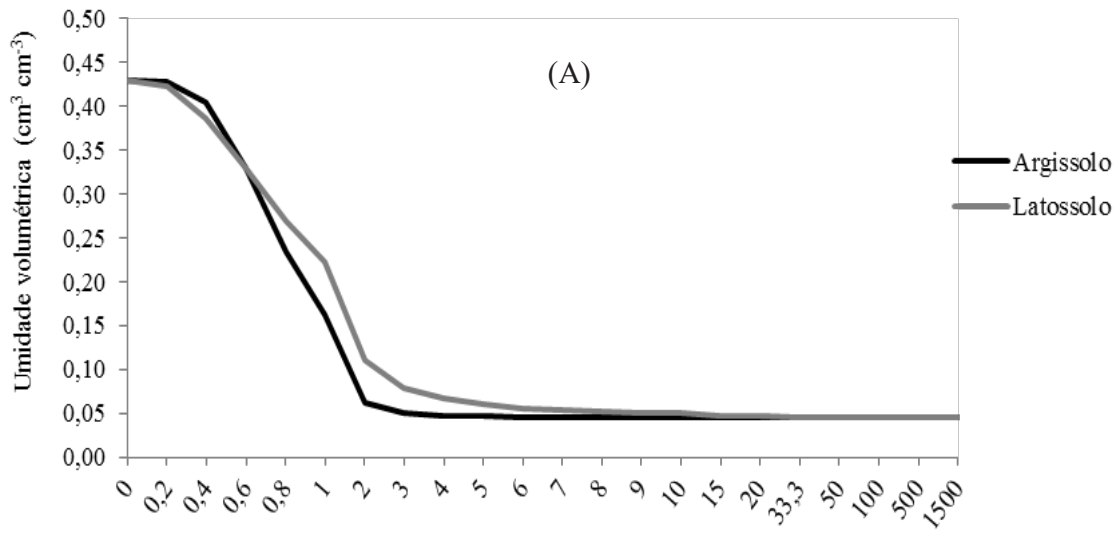

FIGURA 2: Curva de retenção de umidade em diferentes classes de solo nas profundidades de 0-0,5 m (A) e 0,10-0,15 m (B) no Parque Estadual Dois Irmãos (PEDI) em Pernambuco.

FIGURE 2: Moisture retention curve in different soil classes on depths 0-0.05 $\mathrm{m}(\mathrm{A})$ and $0.10-0.15 \mathrm{~m}(\mathrm{~B})$ in the State Park Dois Irmãos (PEDI) in Pernambuco state.

\section{CONCLUSÕES}

Os solos do PEDI apresentaram baixa fertilidade natural, com reação ácida e com elevadas concentrações de $\mathrm{Al}^{3+}$ até $0,60 \mathrm{~m}$ de profundidade, que podem formar barreiras químicas prejudicando o crescimento das raízes das plantas, causando a frequente queda de árvores no Parque.

\section{AGRADECIMENTOS}

Ao Parque Estadual Dois Irmãos pela permissão para a coleta das amostras, a Secretaria de Educação do Estado de Pernambuco pela cessão para realização do Curso de Mestrado e ao Programa de Pós-Graduação em Ciências Florestais da Universidade Federal Rural de Pernambuco pelos conhecimentos adquiridos.

\section{REFERÊNCIAS}

ALVAREZ V.V. Het al. Interpretação dos resultados das análises de solos. In: RIBEIRO, A. C.; GUIMARÃES, P. T. G.; ALVAREZ V. V. H. (Ed.). Recomendações para o uso de corretivos e fertilizantes em Minas Gerais. $5^{\text {a }}$ Aproximação. Viçosa, MG: Comissão de Fertilidade do Solo do Estado de Minas Gerais, 1999. 
p. 25-32.

BOTREL, R. T. et al. Influência do solo e topografia sobre as variações da composição florística e estrutura da comunidade arbóreo-arbustiva de uma floresta estacional semidecidual em Ingaí-MG. Revista Brasileira de Botânica, São Paulo, v. 25, p. 195-213, 2002.

CALDAS, A. M. Solos, antropização e morfometria da microbacia do prata, Recife-PE. 2007. 130 f. Dissertação (Mestrado em Engenharia Agrícola) - Universidade Federal Rural de Pernambuco, Recife, 2007.

CARVALHO, D. A. et al. Distribuição de espécies arbóreo-arbustivas ao longo de um gradiente de solos e topografia em um trecho de floresta ripária do Rio São Francisco em Três Marias, MG, Brasil. Revista Brasileira de Botânica, São Paulo, v. 28, p. 329-345, 2005.

CITADINI-ZANETTE, V. Florística, fitossociologia e aspectos da dinâmica de um remanescente de mata atlântica na microbacia do rio Novo, Orleans, SC. 1995. 249 f. Tese (Doutorado em Ecologia e Recursos Naturais) - Universidade Federal de São Carlos, São Carlos, 1995.

COLLARES et al. Qualidade física do solo na produtividade da cultura do feijoeiro num Argissolo. Pesquisa Agropecuária Brasileira, Brasília, v. 41, n. 11, p. 1663-1664, 2006.

CORREAA, M. M. et al. Formas de ferro, silício e, ou, alumínio na gênese de fragipãns e horizontes coesos dos Tabuleiros Costeiros. Revista Brasileira de Ciência do Solo, Viçosa, MG, v. 39, p. 940-949, 2015.

COUTINHO, R. Q.; LIMA FILHO, M. F.; SOUZA NETO, J. B. Características climáticas, geológicas, geomorfológicas e geotécnicas da Reserva Ecológica de Dois Irmãos. In: MACHADO, I. C.; LOPES, A. V.; PÔRTO, K. C. (Org.). Reserva Ecológica de Dois Irmãos: estudos em um remanescente de Mata Atlântica em área urbana. Recife: Editora Universitária da UFPE, 1998. 326 p.

CUNHA, J. C. et al. Quantification of permanent and variable charges in reference soils of the state of Pernambuco, Brazil. Revista Brasileira de Ciência do Solo, Viçosa, MG, v. 38, p. 1162-1169, 2014.

DALANESI, P. E.; OLIVEIRA FILHO, A. T.; FONTES, M. A. L. Flora e estrutura do componente arbóreo da floresta do Parque Ecológico Quedas do Rio Bonito, Lavras, MG, e correlações entre a distribuição das espécies e variáveis ambientais. Acta Botanica Brasilica, Belo Horizonte, v. 18, p. 737-757, 2004.

DANTAS, J. S. et al. Gênese de solos coesos do leste maranhense: relação solo-paisagem. Revista Brasileira de Ciência do Solo, Viçosa, MG, v. 38, p. 1039-1050, 2014.

EMBRAPA. Manual de análises químicas de solos, plantas e fertilizantes. 2. ed. rev. ampl. Brasília: Embrapa Informação Tecnológica, 2009. 627 p.

EMBRAPA. Manual de métodos de análise de solo. 2. ed. Rio de Janeiro: Embrapa Solos, 1997. 212 p.

ESPIG, S. A. et al. Composição e eficiência da utilização biológica de nutrientes em fragmento de Mata Atlântica. Ciência Florestal, Santa Maria, v. 18, n. 3, p. 307-314, 2008.

ESPIG, S. A. et al. Sazonalidade, composição e aporte de nutrientes da serrapilheira em fragmento de Mata Atlântica. Revista Árvore, Viçosa, MG, v. 33, p. 949-956, 2009.

FERREIRA, I. C. M. et al. Solos e vegetação nativa remanescente no Município de Campinas. Pesquisa Agropecuária Brasileira, Brasília, v. 42, n. 9, p. 1319-1327, 2007.

GAMA, J. R. N. F.; KIEHL, J. C. Influência do alumínio de um Podzólico Vermelho-Amarelo do Acre sobre o crescimento das plantas. Revista Brasileira de Ciência do Solo, Viçosa, MG, v. 23, p. 475-482, 1999.

HARTWIG, I. et al. Mecanismos associados à tolerância ao alumínio em plantas. Semina: Ciências Agrárias, Londrina, v. 28. n. 2, p. 219-228, 2007.

INSTITUTO BRASILEIRO FLORESTAL. Bioma Mata Atlântica. [2015]. Disponível em: <http://www. ibflorestas.org.br/bioma-mata-atlantica.h>. Acesso em: 23 jun. 2015.

JACOMINE, P. K. T. et al. Levantamento exploratório - reconhecimento de solos do Estado de Pernambuco. Recife: Embrapa Centro de Pesquisas Pedológicas, 1973. 713 p. (Boletim Técnico, 26).

JORDAN, C. F. Nutrient cycling processes and tropical forest management. In: GÓMEZ-POMPA, A.; WHITMORE, T. C.; HADLEY, M. (Ed.). Rain forest regeneration and management. New York: UNESCO, 1991. p. 1159-1180.

LEAL, L.; BIONDI, D.; BATISTA, A. C. Influência das florestas urbanas na variação termo-higrométrica da área intraurbana de Curitiba - PR. Ciência Florestal, Santa Maria, v. 24, n. 4, p. 807-820, 2014.

LIMA, M. G. C.; CORRÊA, A. C. B. Apropriação de uma unidade de Conservação de Mata Atlântica no

Ci. Fl., v. 28, n. 2, abr. - jun., 2018 
espaço urbano de Recife - PE: o caso da Reserva de Dois Irmãos. Revista de Geografia, Campo Grande, v. 22 , p. 67-77, 2005.

MAFRA, A. L. et al. Carbono orgânico e atributos químicos do solo em áreas florestais. Revista Árvore, Viçosa, MG, v. 32, p. 217-224, 2008.

MARIN, A. M. P. Impactos de um sistema agroflorestal com café na qualidade do solo. 2002. 156 f. Tese (Doutorado em Solos e Nutrição de Plantas) - Universidade Federal de Viçosa, Viçosa, MG, 2002.

MITTERMEIER, R. A. et al. Hotspots revisited: earth's biologically richest and most endangered terrestrial ecoregions. 2nd ed. Boston: University of Chicago Press, 2005. 392 p.

MOREIRA, E. B. M.; GALVÍNCIO, J. D. Espacialização das temperaturas à superfície na cidade do Recife, utilizando imagens TM - LANNDSAT 7. Revista de Geografia, Campo Grande, v. 24, p. 101-115, 2007.

NOVAIS, R. F.; SMYTH, T. J. Fósforo em solo e planta em condições tropicais. Viçosa, MG: Universidade Federal de Viçosa, Departamento de Solos, 1999. 399 p.

RIBEIRO, M. C. et al. The brazilian forest: how much is left, and how is remaining forest distributed? implications for conservation. Biological conservation, Essex, v. 142, n. 6, p. 1141-1153, 2009.

ROSSI, M. et al. Relação solo/vegetação em área natural no Parque Estadual de Porto Ferreira, São Paulo. Revista do Instituto Florestal, São Paulo, v. 17, p. 45-61, 2005.

RUGGIERO, P. G. C. et al. Relação entre solo, vegetação e topografia em área de cerrado (Parque Estadual de Vassununga, SP): como se expressa em mapeamentos? Acta Botanica Brasilica, Belo Horizonte, v. 20, p. 383-394, 2006.

RUIZ, H. A. Incremento da exatidão da análise granulométrica do solo por meio da coleta da suspensão (Silte + Argila). Revista Brasileira de Ciência do Solo, Viçosa, MG, v. 29, n. 2, p. 297-300, 2005.

SANTOS, H. G. et al. (Org.). Sistema brasileiro de classificação de solos. 3. ed. rev. ampl. Brasília: Embrapa, 2013. 353 p.

SANTOS, J. C. B. Caracterização de neossolos regolíticos da região semi-árida do estado de Pernambuco. 2011. 102 f. Dissertação (Mestrado em Ciência do Solo) - Universidade Federal Rural de Pernambuco, Recife, 2011.

SILVA, R. B. M. et al. Relação solo/vegetação em ambiente de Cerrado sobre influência do grupo Urucuia. Ciência Florestal, Santa Maria, v. 25, p. 363-373, 2015.

TOMÉ JÚNIOR, J. B. Manual para interpretação de análise de solo. Guaíba: Agropecuária Técnica, 1997. $123 \mathrm{p}$.

VAN GENUCHTEN, M. T. A. A closed-form equation for predicting the hydraulic conductivity of unsaturated soils. Soil Science Society of America Journal, Madison, v. 44, p. 892-898, 1980. 